\title{
Triple-A syndrome: a wide spectrum of adrenal dysfunction
}

\author{
Florence Roucher-Boulez ${ }^{1,2,3}$, Aude Brac de la Perriere, ${ }^{3,4}$, Aude Jacquez², Delphine Chau², Laurence Guignat ${ }^{5}$, \\ Christophe Vial', Yves Morel ${ }^{1,2,3}$, Marc Nicolino ${ }^{2,3,7}$, Gerald Raverot ${ }^{2,4}$ and Michel Pugeat $^{2,4}$
}

${ }^{1}$ Laboratoire de Biochimie et Biologie Moléculaire Grand Est, UM Pathologies Endocriniennes Rénales Musculaires et Mucoviscidose, Groupement Hospitalier Est, Hospices Civils de Lyon, Bron, France, ${ }^{2}$ Univ Lyon, Université Claude Bernard Lyon 1, Lyon, France, ${ }^{3}$ Centre de Référence du Développement Génital: du Fœtus à l'Adulte, Filière Maladies Rares Endocriniennes, Bron, France, ${ }^{4}$ Fédération d'Endocrinologie, Groupement Hospitalier Est, Hospices Civils de Lyon, Bron, France, ${ }^{5}$ Service d'Endocrinologie, Centre de Référence des Maladies Surrénaliennes Rares, Hôpital Cochin, Paris, France, ${ }^{6}$ Service d'Electroneuromyographie et Pathologies Neuromusculaires, Groupement Hospitalier Est, Hospices Civils de Lyon, Bron, France, and ${ }^{7}$ Service de Pédiatrie Endocrinologie, Groupement Hospitalier Est, Hospices Civils de Lyon, Bron, France

Correspondence should be addressed to F Roucher-Boulez Email

florence.roucher@chu-lyon.fr

\begin{abstract}
Objective: Triple-A or Allgrove syndrome is an autosomal recessive disorder due to mutations in the AAAS gene, which encodes a nucleoporin named ALADIN. It is characterized by a classical clinical triad: alacrima, achalasia and adrenal insufficiency, the canonic symptoms that are associated with progressive peripheral neuropathy. Only a few cohorts have been reported. The objective of the present study was to characterize the various spectra of adrenal function in Triple-A patients.

Methods: A retrospective clinical and biological monitoring of 14 patients (10 families) was done in a single multidisciplinary French center. All had AAAS gene sequenced and adrenal function evaluation.

Results: Nine different AAAS mutations were found, including one new mutation: c.755G>C, p.(Trp252Ser). Regarding adrenal function, defects of the zona fasciculata and reticularis were demonstrated by increased basal ACTH levels and low DHEAS levels in all cases regardless of the degree of glucocorticoid deficiency. In contrast, mineralocorticoid function was always conserved: i.e., normal plasma renin level associated with normal aldosterone level. The main prognostic feature was exacerbation of neuropathy and cognitive disorders.

Conclusions: These data suggest that, in Triple-A patients, adrenal function can be deficient, insufficient or compensated. In our cohort after the first decade of life, there does not appear to be any degradation of adrenal function over time. However, patients with compensated adrenal function should be informed and educated to manage a glucocorticoid replacement therapy in case of stressful conditions, with no need for systematic long-term treatment.
\end{abstract}

\section{Introduction}

Triple-A syndrome, also known as Allgrove syndrome (OMIM \#231550), was identified in 1978, as a familial glucocorticoid deficiency with achalasia of the cardia and deficient tear production (1). It is a neglected disease, commonly manifesting with the triad of adrenal insufficiency, achalasia of the esophageal cardia and alacrima (AAA). Additionally, most triple-A patients suffer from progressive neurological degenerative features. Neurological disorders include pyramidal syndrome, motor and sensory peripheral neuropathy, autonomic disorders, bulbar dysfunction, optical atrophy and ataxia (2). After adrenal insufficiency and achalasia have been corrected, worsening of neurologic impairment seems to be a major prognostic factor for triple-A syndrome (3). 
The triad may be incomplete, alacrima being the earliest and the most constant symptom while achalasia is the main complaint leading to specialist consultation $(4,5)$. Adrenal insufficiency due to glucocorticoid secretion deficiency is reported in $85 \%$ of patients, and usually develops in the first, or more rarely the second decade of life. In contrast, mineralocorticoid deficiency is reported in only $15 \%$ patients $(4,6,7)$. The full triad is found in almost two-thirds of patients, 2 symptoms in one-third, and only 1 symptom in less than $10 \%$ of patients $(8,9)$.

Triple-A syndrome is an autosomal recessive disorder due to pathological mutations in the $A A A S$ gene, which encodes a nucleoporin named ALADIN (for ALcrima, Achalasia, aDrenal Insufficiency, Neurologic disorder), inducing progressive neuropathy (10). ALADIN is one of the nucleoporins constituting the nuclear pore complex (NPC) and belongs to the WD-repeat protein family. NPC is a large protein structure, spanning the double nuclear membrane and enabling nucleocytoplasmic exchange (11). ALADIN mutations lead to mistargeting of the protein in the NPC. This impairs nuclear importation of DNArepair proteins (aprataxin and DNA ligase I) and ferritin heavy-chain (FTH1) involved in nuclear defense against oxidative stress $(12,13)$. The resulting hypersensitivity to oxidative stress may explain the gradual progression of triple-A symptoms (13).

The $A A A S$ gene shows ubiquitous expression in human tissue, with elevated expression in the adrenal gland, gastrointestinal structures, pituitary gland and cerebellum that may account for the wide clinical spectrum of triple-A syndrome (14).

Most previous reports focused on genetics and/or were limited to case reports. Only a few studies reported follow-up $(8,9,15)$. The objective of the present paper was to document the various spectra of adrenal function in terms of the clinical presentation and genetic characterization of 14 patients from 10 families.

\section{Patients and methods}

\section{Patients}

Fourteen triple-A patients ( 7 males, 7 females) from 10 families, followed in pediatric and adult endocrinology departments in Lyon (France), were enrolled in a retrospective study. Informed consent was provided, and the study was conducted in accordance with the principles of the Declaration of Helsinki. Patients were eligible if they showed 2 or 3 symptoms of the classical triple-A triad and abnormal AAAS gene analysis. The neurological symptoms of families $1,5,7,8$ and 10 were previously described by Vallet and coworkers (2).

\section{Molecular genetic analysis of the AAAS gene}

\section{Sanger sequencing}

Genomic DNA was extracted from EDTA-preserved whole blood using the Nucleon BACC3 kit (GE Healthcare).

Selective amplification of the 16 coding exons of the $A A A S$ gene was performed in 6 fragments by PCR using specific primers (available on request). Conventional dideoxy Sanger sequencing of exons and exon-intron boundaries was performed using Big-Dye Terminators. Sequencing products were loaded on an ABI-3730XL DNA analyzer and analyzed using SeqScape software v3 (Life Technologies). Sequence variants were designated according to the Human Genome Society guidelines (www. hgvs.org/rec.html) using the NCBI reference sequences NC_000012.11, NM_015665.5 and NP_056480.1 built on the GRCh37/hg19 databases.

\section{Pathogenicity prediction}

For the new missense mutation, pathogenicity was predicted in silico using 3 programs: Polyphen 2, SIFT and Mutation taster. Grantham score was calculated to predict the effect of substitution between amino acids, with scores between 0 and 215, based on chemical properties; higher scores indicate greater differences in chemical properties (polarity and molecular volume) between two amino acids, and may indicate a stronger negative impact on protein structure and function. The dbSNP, EVS and ExAC browser databases were searched to determine whether the variant had already been reported.

\section{Plasma immunoassays}

Plasma ACTH (adrenocorticotropic hormone) and cortisol levels were measured by electro-chemiluminescent assays (ECLIA) on a cobas e601 analyzer (Roche Diagnostics $\mathrm{GmbH})$. Reference ranges were $14-26 \mathrm{ng} / \mathrm{L}$ for ACTH and $350-500 \mathrm{nmol} / \mathrm{L}$ for cortisol. Adrenal function was further investigated by ACTH (Synacthen) stimulation test and was considered normal for cortisol concentration $>500 \mathrm{nmol} / \mathrm{L}$.

Plasma aldosterone was determined on aldosterone radioimmunoassay (RIA) (Beckman Immunotech). Normal ranges were $40-85 \mathrm{pmol} / \mathrm{L}$ in supine position and 275-415 pmol/L in standing position. 
Renin was measured with a renin III generation kit (Cisbio International, Saclay, France) before 2014, and then by automated ECLIA on an ISYS analyzer (IDS) calibrated according to the WHO international standard $68 / 356$ (1.67 IU/L=1 ng/L). Ranges were $11-71 \mathrm{ng} / \mathrm{L}$ between the ages of 3 and 11 years, and $2.51-35.7 \mathrm{ng} / \mathrm{L}$ in supine position and $3.17-59.3 \mathrm{ng} / \mathrm{L}$ in standing position for adults.

Plasma DHEAS was measured with an in-house competitive method using in-house rabbit anti-human DHEAS antibodies (16). Mean values for both genders before puberty were $59 \pm 41 \mathrm{nmol} / \mathrm{L}$ for 1 - to 5 -yearolds and $320 \pm 250 \mathrm{nmol} / \mathrm{L}$ for 6 - to 9-year-olds; then, according to pubertal status, P1: $1800 \pm 620 \mathrm{nmol} / \mathrm{L}$, $\mathrm{P} 2: \quad 1400 \pm 700 \mathrm{nmol} / \mathrm{L}, \quad$ P3: $\quad 1850 \pm 1300 \mathrm{nmol} / \mathrm{L}, \quad \mathrm{P} 4:$ $2425 \pm 1330 \mathrm{nmol} / \mathrm{L}$ and P5: $3120 \pm 1310 \mathrm{nmol} / \mathrm{L}$; for adults, ranges were $2449-8163 \mathrm{nmol} / \mathrm{L}$ for females and $4082-9524 \mathrm{nmol} / \mathrm{L}$ for males.

\section{Results}

\section{Clinical and biological data}

Table 1 presents the clinical and molecular data for the 14 patients.

Ages ranged from 10 to 79 years, with follow-up of 6-50 years. The complete triad (alacrima, achalasia and adrenal insufficiency) was present in 9 cases, adrenal function was subnormal in 4 (patients 7, 8, 9 and 10; see below) and achalasia was absent in 1 (patient 2B). Mean age at onset of the first symptom leading to consultation was 7 years (range, 2-13 years). Neonatal alacrima was the earliest symptom. However, the first evidence of triple-A syndrome was adrenal insufficiency in 9 patients, achalasia in 3 and neurological symptoms in 2 .

Achalasia was present in 12 patients, with age at onset ranging from 5 to 29 years, and was treated by balloon dilation; 10 patients also required myotomy. Five patients showed low body mass index (BMI) $\left(<18.5 \mathrm{~kg} / \mathrm{m}^{2}\right)$, likely due to more severe achalasia and difficulty feeding.

Ten patients showed adrenal insufficiency, diagnosed during the first decade of life except in 1 patient; mean age at onset was 6.3 years (range, 2-16 years). Adrenal function was evaluated before hydrocortisone administration in patients requiring replacement therapy (Table 2). Independent of glucocorticoid status, all 14 patients showed ACTH elevation. Seven showed severe glucocorticoid deficiency and 4 had dramatically high basal ACTH levels (patients 2A, 2B, 3, 4A) associated with very low basal and ACTH-stimulated cortisol levels (when performed). Three patients had moderate glucocorticoid deficiency with low basal and ACTH-stimulated cortisol levels and required intermittent corticosteroid replacement or continued low-dose corticosteroids. Four patients did not show adrenal insufficiency, but their glucocorticoid deficiency was classified as borderline, with normal cortisol levels but elevated ACTH and appropriate cortisol increase after ACTH challenge. Despite this apparently normal response, patients 7 and 8 received glucocorticoid replacement therapy in an attempt to prevent adrenal crisis in case of progressive disease and for asthenia. Patient 10 showed only neurological symptoms; he was 72 years old when tested, and died at the age of 79 years. DHEAS levels were lower than the age-linked reference range in all tested patients (Table 2). In contrast, none of the patients had mineralocorticoid deficiency, as shown by normal renin and aldosterone levels. Despite normal mineralocorticoid function, 4 patients received fludrocortisone replacement for orthostatic hypotension (Table 3).

Orthostatic hypotension is one of the dysautonomic symptoms seen in triple-A syndrome. Fludrocortisone replacement was transitionally administered, then switched to midodrine, with significant improvement in hypotension in 3 patients $(5 \mathrm{~A}, 8,10)$ (Table 3$)$. Clinically, neurological disorders, others than achalasia or alacrima, were observed in all except 2 patients, aged 15 and 10 years respectively (patients $2 \mathrm{~B}$ and 3 ) (Tables 1 and $3)$. Age at onset was variable, ranging from 4 to 25 years, for a mean 11.5 years (Table 1). The long neurological follow-up (10-67 years) showed a progressive worsening of neurological symptoms.

Dental abnormalities were also observed: caries and periodontal disease (patients $1 \mathrm{~A}, 1 \mathrm{~B}, 5 \mathrm{~A}$ ), premature tooth loss (patient 1A), hypodontia and enamel defect (patient $2 \mathrm{~A})$.

\section{AAAS gene sequencing}

Nine different $A A A S$ mutations were identified in the 910 families (Table 1). All had already been reported (2, 10, $14,17,18,19,20)$, except one: c.755G $>$ C or p.(Trp252Ser) (Fig. 1). This mutation was homozygous in the 2 brothers of family 2, a consanguineous Gypsy family. It is located in one of the WD repeat domains that is highly conserved between species (14). It has not been reported in any databases (dbSNP, ExAC browser or ESP) and was predicted to be deleterious by all the mutation prediction tools (Polyphen-2, SIFT and Mutation Taster), with a high Grantham score of 177 . 


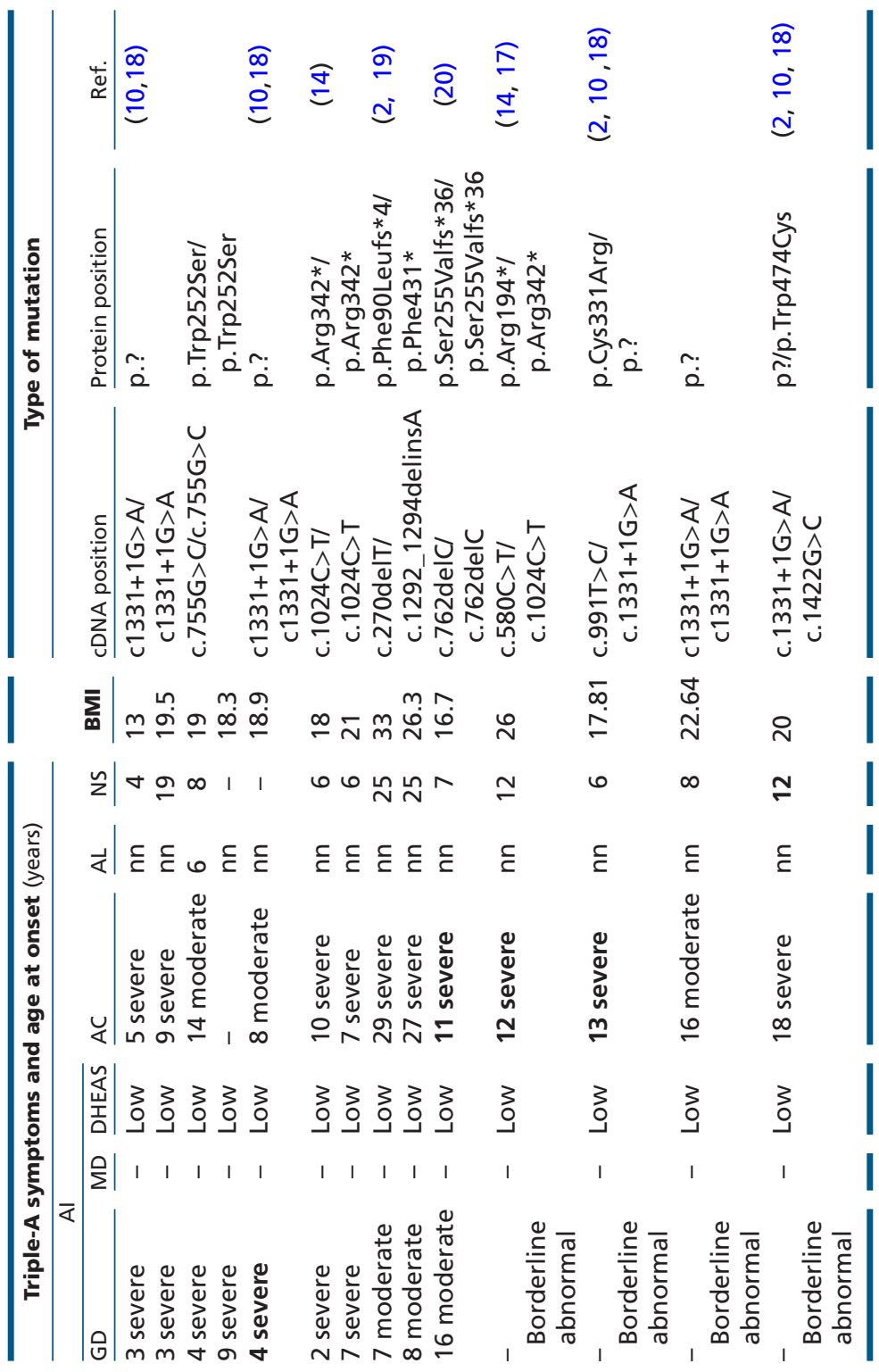

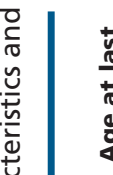

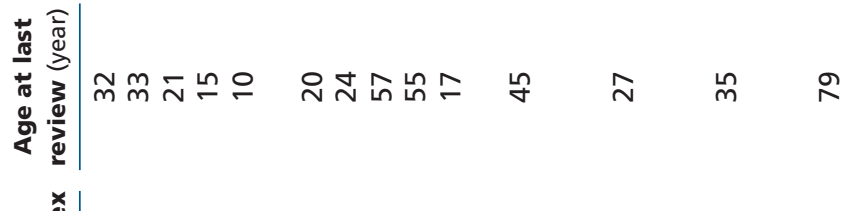

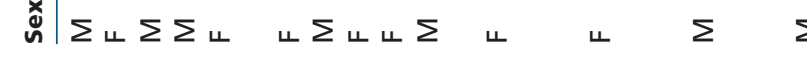

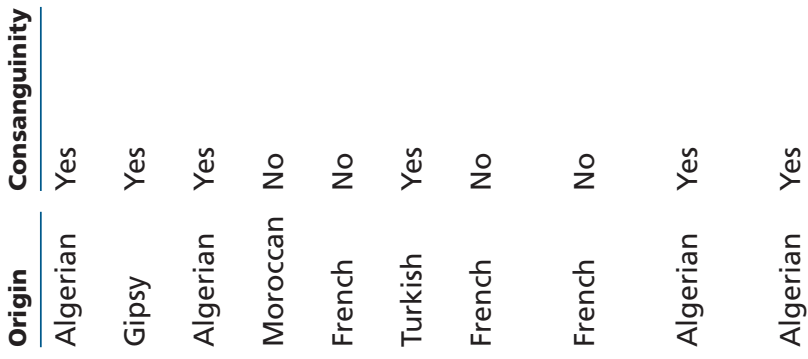

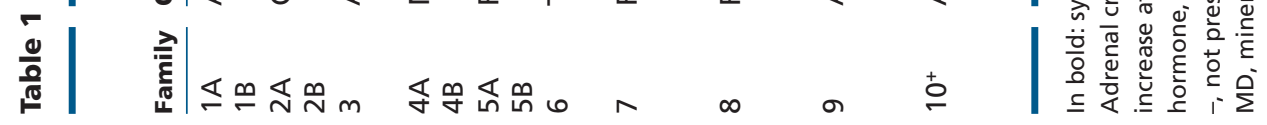


Table 2 Hormone tests.

\begin{tabular}{|c|c|c|c|c|c|c|c|c|c|}
\hline Patients & & $\begin{array}{c}\text { Age at } \\
\text { test (years) }\end{array}$ & $\begin{array}{c}\text { ACTH 8h } \\
\text { (ng/L) }\end{array}$ & $\begin{array}{l}\text { Cortisol 8h } \\
(\mathrm{nmol} / \mathrm{L})\end{array}$ & $\begin{array}{c}\text { Cortisol after } 60 \mathrm{~min} \\
\text { under Synacthene }(\mathrm{nmol} / \mathrm{L})\end{array}$ & $\begin{array}{l}\text { Aldosterone } \\
(\mathrm{pmol} / \mathrm{L})\end{array}$ & $\begin{array}{c}\text { Renin } \\
\text { (ng/L) }\end{array}$ & $\begin{array}{l}\text { DHEAS } \\
\text { (nmol/L) }\end{array}$ & GD classification \\
\hline \multirow[t]{2}{*}{$1 \mathrm{~A}$} & $A$ & 3 & 317 & 72 & - & 52 & 2 & - & Severe \\
\hline & B & 21 & 374 & 88 & 57 & 103 & $5.2 *$ & 1326 & Severe \\
\hline \multirow[t]{2}{*}{$1 \mathrm{~B}$} & $A$ & 3 & 683 & 77 & 77 & - & 10.3 & - & Severe \\
\hline & $B$ & 24 & 182 & 51 & $<43$ & 35 & $12^{*}$ & 198 & Severe \\
\hline \multirow[t]{2}{*}{$2 \mathrm{~A}$} & $A$ & 4 & 2096 & $<30$ & - & - & 76 & & Severe \\
\hline & $B$ & 19 & 1141 & 38 & 31 & 85 & $36 *$ & 1064 & Severe \\
\hline \multirow[t]{2}{*}{$2 \mathrm{~B}$} & $A$ & 9 & $>2000$ & - & - & - & 13 & & Severe \\
\hline & $B$ & 15 & $>2000$ & - & - & 94 & $28 *$ & 1468 & Severe \\
\hline \multirow[t]{2}{*}{3} & $A$ & 4 & 3499 & 99 & - & 172 & 14 & $<40$ & Severe \\
\hline & $B$ & 10 & 750 & - & - & 23 & 23 & $<40$ & Severe \\
\hline \multirow[t]{2}{*}{$4 \mathrm{~A}$} & A & 2 & - & $<30$ & - & - & - & - & Severe \\
\hline & B & 20 & 446 & 51 & 60 & 48 & 27 & 245 & Severe \\
\hline \multirow[t]{2}{*}{$4 B$} & A & 7 & - & $<30$ & 485 & - & - & - & Severe \\
\hline & B & 24 & 352 & 86 & 92 & 99 & 12 & 2576 & Severe \\
\hline \multirow[t]{2}{*}{$5 \mathrm{~A}$} & $A$ & 14 & 1971 & - & - & - & 20 & - & Moderate \\
\hline & B & 58 & 341 & 332 & 422 & 149 & $11 *$ & 111 & Moderate \\
\hline \multirow[t]{2}{*}{$5 B$} & A & 32 & 85 & 483 & - & 277 & 60 & - & Moderate \\
\hline & B & 42 & 129 & 248 & 424 & 132 & $3.5^{*}$ & 1318 & Moderate \\
\hline \multirow[t]{2}{*}{6} & $A$ & 11 & 57 & 385 & - & - & 25 & - & Moderate \\
\hline & B & 16 & 222 & 264 & 245 & - & $49 *$ & - & Moderate \\
\hline \multirow[t]{2}{*}{7} & $A$ & 38 & - & 258 & 596 & - & - & - & $\begin{array}{l}\text { Borderline } \\
\text { abnormal }\end{array}$ \\
\hline & B & 41 & 32 & 211 & 511 & 58 & $8^{*}$ & 270 & $\begin{array}{l}\text { Borderline } \\
\text { abnormal }\end{array}$ \\
\hline \multirow[t]{2}{*}{8} & A & 19 & 107 & $911^{\text {ㅁ }}$ & $1263^{\circ}$ & 577 & 12 & 43 & $\begin{array}{l}\text { Borderline } \\
\text { abnormal }\end{array}$ \\
\hline & B & 26 & - & $1575^{*}$ & & 26 & $<3$ & $<6$ & $\begin{array}{l}\text { Borderline } \\
\text { abnormal }\end{array}$ \\
\hline \multirow[t]{2}{*}{9} & $A$ & 32 & 189 & 490 & 676 & 790 & 15 & 1698 & $\begin{array}{l}\text { Borderline } \\
\text { abnormal }\end{array}$ \\
\hline & B & 35 & 85 & 384 & 602 & 135 & 5 & 2407 & $\begin{array}{l}\text { Borderline } \\
\text { abnormal }\end{array}$ \\
\hline \multirow[t]{2}{*}{10} & $A$ & 73 & 71 & 601 & 1022 & 125 & 2 & 2526 & $\begin{array}{l}\text { Borderline } \\
\text { abnormal }\end{array}$ \\
\hline & B & 75 & 60 & 532 & 723 & 33 & 5 & - & $\begin{array}{l}\text { Borderline } \\
\text { abnormal }\end{array}$ \\
\hline
\end{tabular}

Adrenal criteria, as defined in Table 1. Reference ranges are defined in the method section and values not in range are in bold.

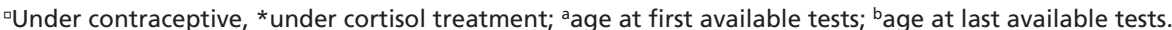

-, not evaluated; GD, glucocorticoid deficiency.

The known mutations found in our series were frameshift or nonsense mutations that encode for premature truncated proteins or absence of protein implicating the nonsense-mediated decay system. As expected, mutation c.1131+1G $>A$, the predominant mutation found in North African countries, was found in the North African families in the series except in family 4 where the mutation found was p.Arg342* and in family 10 for whom there was an additional mutation p.Trp474Cys.

\section{Discussion}

We report long follow-up in 14 patients with triple-A syndrome associated with $A A A S$ gene mutations. Clinical findings were in agreement with those of the few cohort studies. The complete clinical triple-A triad is present in $70 \%$ of cases and revealed during the first decade of life $(8,9,15,20)$. The presenting symptom was adrenal insufficiency in two-thirds of the patients and achalasia or neurological symptoms in one-third, with mean age at onset of 7.3 years. Alacrima was systematic at diagnosis, suggesting early onset. Lastly, as tear loss may result from autonomic nervous system dysfunction and achalasia from central nervous system dysfunction, neurological symptoms appear to be the earliest indicators of triple-A syndrome (21).

In 9 patients, adrenal insufficiency was the presenting symptom, but emerged later in 1 patient, at 16 years of 


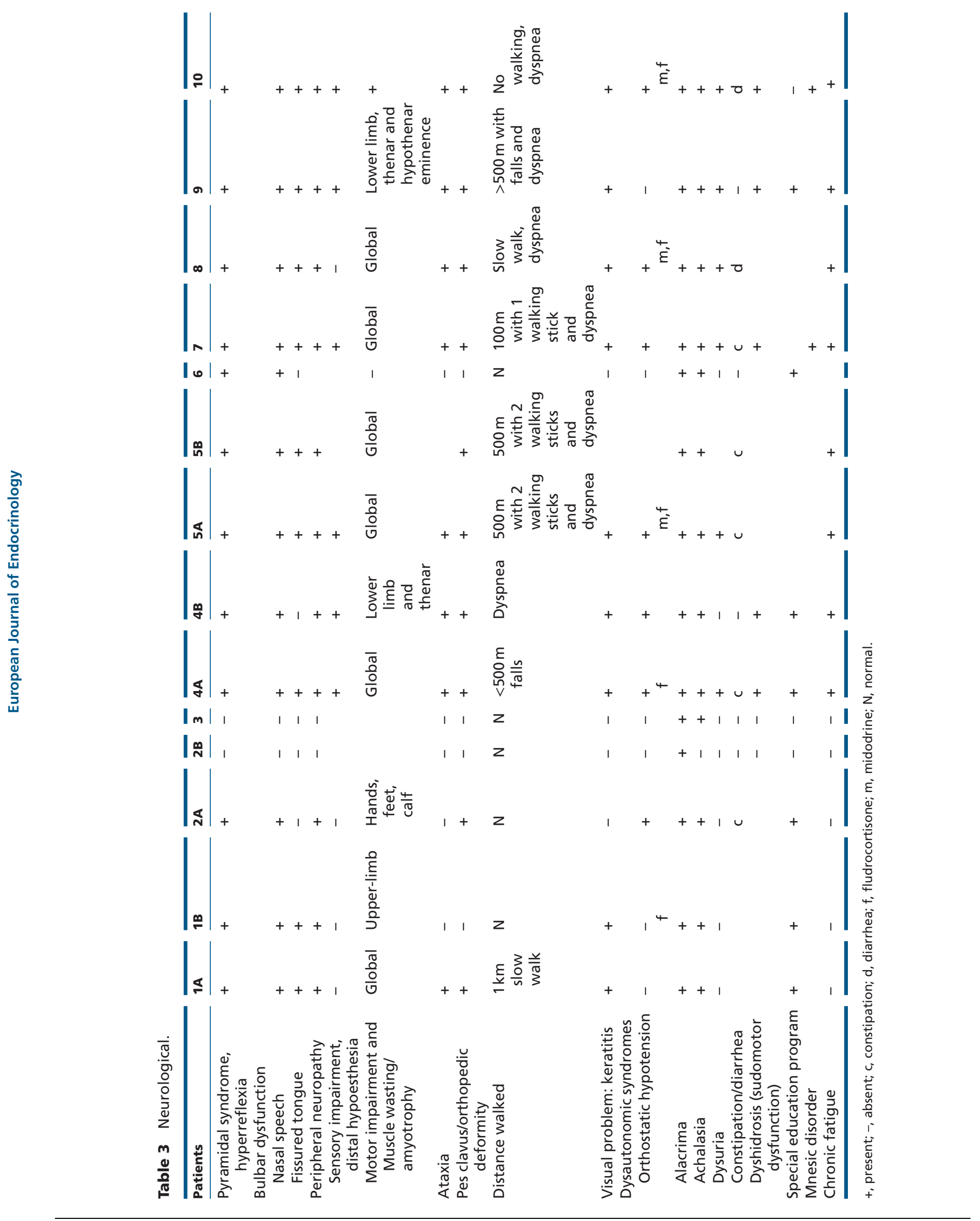


age, probably due to stress. Mild-to-severe symptoms, such as growth retardation and hypoglycemic seizures, revealed adrenal insufficiency. Patients were classified on hormonal exploration as having severe or moderate glucocorticoid deficiency according to basal ACTH elevation with low cortisol level and/or inappropriate increase in cortisol level after ACTH challenge test. However, although glucocorticoid status seemed normal in a few patients, ACTH elevation suggests a zona fasciculata lesion. These patients were classified as having a borderline glucocorticoid secretion compensated for by increased ACTH levels, without any change in adrenal function during the 14-67 years' follow-up. This suggests that there is no need for systematic treatment, but that patients should be informed and educated to manage glucocorticoid replacement therapy in case of stressful conditions. Anyway, follow-up of the adrenal function should still be recommended all lifelong.

Triple-A syndrome is characterized by glucocorticoid deficiency, but normal renin and aldosterone levels suggest that mineralocorticoid secretion is conserved. These results diverge from the 15 mineralocorticoid deficit reported elsewhere $(4,7)$. One hypothesis for the relative conservation of the zona glomerulosa could be reduced production of reactive oxygen species during aldosterone biosynthesis, which is in $\mathrm{pmol} / \mathrm{L}$, unlike cortisol biosynthesis, which is in $\mathrm{nmol} / \mathrm{L}$ in the zona fasciculata (22). ALADIN mutations cause selective failure of nuclear importation of DNA repair and anti-oxidant proteins and hypersensitivity to oxidative stress $(12,23)$. Oxidative stress impedes steroidogenesis, which in turn increases oxidative stress resulting from electron leaks throughout the steroidogenic pathway.

Interestingly, as already reported in the literature, we found low adrenal androgen levels (DHEAS) in all patients tested (24). This suggests that progressive degeneration of the zona reticularis is associated with abolished steroidogenesis in the zona fasciculata. This hypothesis is sustained by the reported atrophy of zonae fasciculata and reticularis in triple-A patients (1). Cortical cell renewal is centripetal. Progenitors located within a specific niche in the zona glomerulosa are constantly recruited. They initially differentiate as zona glomerulosa cells and undergo lineage conversion to zona fasciculata as they move within the cortex, and then to the zona reticularis (25). Progressive cell degeneration may be induced by gradual oxidative stress in the adrenal cortex. Besides, AAAS knockdown in H295R human adrenocortical cells deregulates proteins involved in the glucocorticoid and androgen pathways of steroidogenesis $(22,26)$. Early DHEAS assay could provide

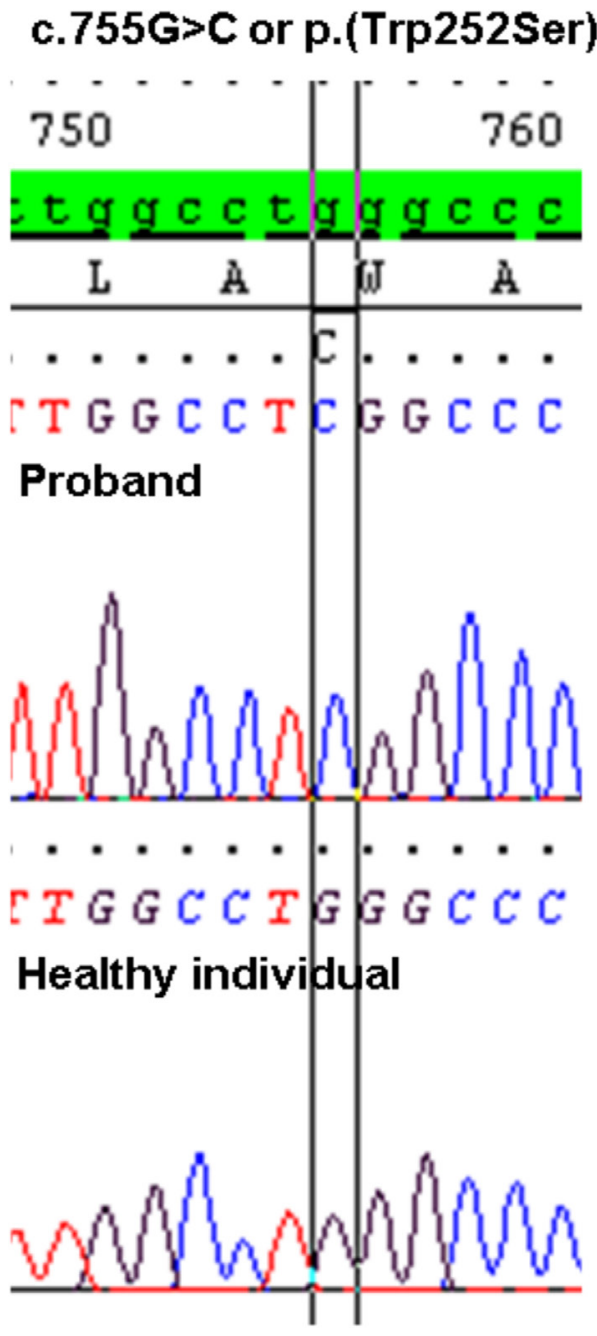

\section{Figure 1}

Partial chromatograms showing the novel AAAS mutations detected in family 2 . Base change c.755G $>C$ leading to the missense mutation p.(Trp252Ser). The reference sequence is in highlighted in green. One of the patients' DNA sequence (proband) is above and a healthy control's sequence underneath.

a good marker of zona reticularis function, enabling the detection of glucocorticoid insufficiency.

As reported elsewhere, the phenotypic variability observed here between patients with the same mutation or within a given family (family 2 ) is consistent with the absence of correlation between genotype and phenotype in triple-A syndrome $(10,14)$. Nine different $A A A S$ mutations were found in the 10 families: frameshift and nonsense mutations and 1 new missense: p.(Trp252Ser). More than 75 causative variations are reported (http:// www.hgmd.cf.ac.uk). Most lead to truncation of the protein C-terminus, which deletes a domain essential 
for NPC targeting. Otherwise, missense mutations in the conserved WD-repeat domain probably disrupt protein folding and the localization in the $\operatorname{NPC}(12,23)$. The protein impact of the mutations does not predict symptom severity or whether the syndrome will be complete or not.

Follow-up showed that all patient except one developed achalasia, and perhaps earlier in case of severe adrenal insufficiency. But the main prognostic feature seemed to be exacerbation of neuropathy and cognitive disorders. Age at onset of neurological disorder is variable, and can be late, as in the present cohort where the age range was $2-25$ years $(2,15,27)$. Although it is often the first symptom of the syndrome, it may mislead diagnosis $(2,28)$. Mutations in the $A A A S$ gene explain $90 \%$ of triple-A cases and the remaining cases may be partly explained by the two novel genes, GMPPA and TRAPPC11, giving a 'triple-A-like' syndrome without adrenal insufficiency $(29,30)$. Massive parallel sequencing (MPS) enables all 3 genes to be assessed in a single test. It confirms or rules out diagnosis in case of misleading symptoms, and identification of a pathogenic mutation in one or another gene allows patient monitoring to be adapted. Likewise, in adrenal insufficiency, which is suspected to be genetic, all the genes most frequently involved may be tested by MPS, allowing suitable monitoring before onset of other symptoms, such as those of triple-A syndrome $(31,32)$.

To conclude, our triple-A patients show a wide spectrum of adrenal dysfunction, with defects in glucocorticoid and androgen biosynthesis that can be compensated for by increased ACTH levels, while mineralocorticoid secretion seems normal. Prognosis seems mainly to depend on progressive neurological deficits.

\section{Declaration of interest}

The authors declare that there are no conflicts of interest that could prejudice the impartiality of this study.

\section{Funding}

This research did not receive any specific grant from any funding agency in the public, commercial or not-for-profit sectors.

\section{Acknowledgment}

The authors thank the Filière Maladies Rares Endocriniennes, FIRENDO.

\section{References}

1 Allgrove J, Clayden GS, Grant DB \& Macaulay JC. Familial glucocorticoid deficiency with achalasia of the cardia and deficient tear production. Lancet 19781 1284-1286. (https://doi.org/10.1016/ S0140-6736(78)91268-0)
2 Vallet AE, Verschueren A, Petiot P, Vandenberghe N, Nicolino M, Roman S, Pouget J \& Vial C. Neurological features in adult Triple-A (Allgrove) syndrome. Journal of Neurology 2012259 39-46. (https:// doi.org/10.1007/s00415-011-6115-9)

3 Dumic M, Barisic N, Kusec V, Stingl K, Skegro M, Stanimirovic A, Koehler K \& Huebner A. Long-term clinical follow-up and molecular genetic findings in eight patients with triple A syndrome. European Journal of Pediatrics 2012171 1453-1459. (https://doi.org/10.1007/ s00431-012-1745-1)

4 Clark AJ \& Weber A. Adrenocorticotropin insensitivity syndromes. Endocrine Reviews 199819 828-843. (https://doi.org/10.1210/ edrv.19.6.0351)

5 Phillip M, Hershkovitz E \& Schulman H. Adrenal insufficiency after achalasia in the triple-A syndrome. Clinical Pediatrics 199635 99-100. (https://doi.org/10.1177/000992289603500208)

6 Milenkovic T, Koehler K, Krumbholz M, Zivanovic S, Zdravkovic D $\&$ Huebner A. Three siblings with triple A syndrome with a novel frameshift mutation in the AAAS gene and a review of 17 independent patients with the frequent p.Ser263Pro mutation. European Journal of Pediatrics 2008167 1049-1055. (https://doi. org/10.1007/s00431-007-0640-7)

7 Collares CV, Antunes-Rodrigues J, Moreira AC, Franca SN, Pereira LA, Soares MM, Elias Junior J, Clark AJ, de Castro M \& Elias LL. Heterogeneity in the molecular basis of ACTH resistance syndrome. European Journal of Endocrinology 2008159 61-68. (https://doi. org/10.1530/EJE-08-0079)

8 Kallabi F, Belghuith N, Aloulou H, Kammoun T, Ghorbel S, Hajji M, Gallas S, Chemli J, Chabchoub I, Azzouz H et al. Clinical and genetic characterization of 26 Tunisian patients with Allgrove syndrome. Archives of Medical Research 201647 105-110. (https://doi. org/10.1016/j.arcmed.2016.04.004)

9 Milenkovic T, Zdravkovic D, Savic N, Todorovic S, Mitrovic K, Koehler K \& Huebner A. Triple A syndrome: 32 years experience of a single centre (1977-2008). European Journal of Pediatrics 2010169 1323-1328. (https://doi.org/10.1007/s00431-010-1222-7)

10 Tullio-Pelet A, Salomon R, Hadj-Rabia S, Mugnier C, de Laet MH, Chaouachi B, Bakiri F, Brottier P, Cattolico L, Penet C et al. Mutant WD-repeat protein in triple-A syndrome. Nature Genetics 200026 332-335. (https://doi.org/10.1038/81642)

11 Cronshaw JM, Krutchinsky AN, Zhang W, Chait BT \& Matunis MJ. Proteomic analysis of the mammalian nuclear pore complex. Journal of Cell Biology 2002158 915-927. (https://doi.org/10.1083/ jcb.200206106)

12 Hirano M, Furiya Y, Asai H, Yasui A \& Ueno S. ALADINI482S causes selective failure of nuclear protein import and hypersensitivity to oxidative stress in triple A syndrome. PNAS 2006103 2298-2303. (https://doi.org/10.1073/pnas.0505598103)

13 Storr HL, Kind B, Parfitt DA, Chapple JP, Lorenz M, Koehler K, Huebner A \& Clark AJ. Deficiency of ferritin heavy-chain nuclear import in triple a syndrome implies nuclear oxidative damage as the primary disease mechanism. Molecular Endocrinology 200923 2086-2094. (https://doi.org/10.1210/me.2009-0056)

14 Handschug K, Sperling S, Yoon SJ, Hennig S, Clark AJ \& Huebner A. Triple A syndrome is caused by mutations in AAAS, a new WD-repeat protein gene. Human Molecular Genetics 200110 283-290. (https:// doi.org/10.1093/hmg/10.3.283)

15 Houlden H, Smith S, De Carvalho M, Blake J, Mathias C, Wood NW \& Reilly MM. Clinical and genetic characterization of families with triple A (Allgrove) syndrome. Brain 2002125 2681-2690. (https:// doi.org/10.1093/brain/awf270)

16 de Peretti E \& Forest MG. Pattern of plasma dehydroepiandrosterone sulfate levels in humans from birth to adulthood: evidence for testicular production. Journal of Clinical Endocrinology and Metabolism 197847 572-577. (https://doi.org/10.1210/jcem-47-3-572)

17 Dusek T, Korsic M, Koehler K, Perkovic Z, Huebner A \& Korsic M. A novel AAAS gene mutation (p.R194X) in a patient with triple 
A syndrome. Hormone Research 200665 171-176. (https://doi. org/10.1159/000092003)

18 Kallabi F, Ben Rhouma B, Baklouti S, Ghorbel R, Felhi R, Keskes L \& Kamoun H. Splicing defects in the AAAS gene leading to both exon skipping and partial intron retention in a Tunisian patient with Allgrove syndrome. Hormone Research in Paediatrics 201686 90-93. (https://doi.org/10.1159/000446539)

19 Thummler S, Huebner A \& Baechler-Sadoul E. Triple A syndrome: two novel mutations in the AAAS gene. BMJ Case Reports 20092009 (https://doi.org/10.1136/bcr.09.2008.0984)

20 Reimann J, Kohlschmidt N, Kappes-Horn K, Stepien-Mehring M, Tolksdorf K \& Kuchelmeister K. G.P.59 Muscle pathology as a diagnostic clue to Allgrove syndrome. Neuromuscular Disorders 24 812. (https://doi.org/10.1016/j.nmd.2014.06.073)

21 Brooks BP, Kleta R, Caruso RC, Stuart C, Ludlow J \& Stratakis CA. Triple-A syndrome with prominent ophthalmic features and a novel mutation in the AAAS gene: a case report. BMC Ophthalmology 20044 7. (https://doi.org/10.1186/1471-2415-4-7)

22 Juhlen R, Idkowiak J, Taylor AE, Kind B, Arlt W, Huebner A \& Koehler K. Role of ALADIN in human adrenocortical cells for oxidative stress response and steroidogenesis. PLOS ONE 201510 e0124582. (https://doi.org/10.1371/journal.pone.0124582)

23 Kind B, Koehler K, Krumbholz M, Landgraf D \& Huebner A. Intracellular ROS level is increased in fibroblasts of triple A syndrome patients. Journal of Molecular Medicine 201088 1233-1242. (https:// doi.org/10.1007/s00109-010-0661-y)

24 Dumic M, Radica A, Sabol Z, Plavsic V, Brkljacic L, Sarnavka V \& Vukovic J. Adrenocorticotropic hormone insensitivity associated with autonomic nervous system disorders. European Journal of Pediatrics 1991150 696-699. (https://doi.org/10.1007/BF01958757)

25 Drelon C, Berthon A, Mathieu M, Martinez A \& Val P. Adrenal cortex tissue homeostasis and zonation: a WNT perspective. Molecular and Cellular Endocrinology 2015408 156-164. (https://doi.org/10.1016/j. mce.2014.12.014)
26 Prasad R, Metherell LA, Clark AJ \& Storr HL. Deficiency of ALADIN impairs redox homeostasis in human adrenal cells and inhibits steroidogenesis. Endocrinology 2013154 3209-3218. (https://doi. org/10.1210/en.2013-1241)

27 Dixit A, Chow G \& Sarkar A. Neurologic presentation of triple A syndrome. Pediatric Neurology 201145 347-349. (https://doi. org/10.1016/j.pediatrneurol.2011.07.003)

28 Salmaggi A, Zirilli L, Pantaleoni C, De Joanna G, Del Sorbo F, Koehler K, Krumbholz M, Huebner A \& Rochira V. Late-onset triple A syndrome: a risk of overlooked or delayed diagnosis and management. Hormone Research 200870 364-372. (https://doi. org/10.1159/000161867)

29 Koehler K, Malik M, Mahmood S, Giesselmann S, Beetz C, Hennings JC, Huebner AK, Grahn A, Reunert J, Nurnberg G et al. Mutations in GMPPA cause a glycosylation disorder characterized by intellectual disability and autonomic dysfunction. American Journal of Human Genetics 201393 727-734. (https://doi.org/10.1016/j. ajhg.2013.08.002)

30 Koehler K, Milev MP, Prematilake K, Reschke F, Kutzner S, Juhlen R, Landgraf D, Utine E, Hazan F, Diniz G et al. A novel TRAPPC11 mutation in two Turkish families associated with cerebral atrophy, global retardation, scoliosis, achalasia and alacrima. Journal of Medical Genetics 201754 176-185. (https://doi.org/10.1136/ jmedgenet-2016-104108)

31 Guran T, Buonocore F, Saka N, Ozbek MN, Aycan Z, Bereket A, Bas F, Darcan S, Bideci A, Guven A et al. Rare causes of primary adrenal insufficiency: genetic and clinical characterization of a large nationwide cohort. Journal of Clinical Endocrinology and Metabolism 2016101 284-292. (https://doi.org/10.1210/jc.2015-3250)

32 Amano N, Narumi S, Hayashi M, Takagi M, Imai K, Nakamura T, Hachiya R, Sasaki G, Homma K, Ishii T et al. Genetic defects in pediatric-onset adrenal insufficiency in Japan. European Journal of Endocrinology 2017177 187-194. (https://doi.org/10.1530/EJE-17. 0027)

Received 4 August 2017

Revised version received 30 October 2017

Accepted 12 December 2017 